\title{
Prospects for Improving the Effectiveness of Chemotherapy in Patients with Tumors
}

\author{
Kulchitsky Vladimir ${ }^{1 *}$, Zamaro Alexandra ${ }^{1}$, Alexandrova Radostina ${ }^{2}$, Potkin Vladimir ${ }^{3}$, Suziedelis Kestusis ${ }^{4}$, \\ Darinskas Adas ${ }^{4}$, Koulchitsky Stanislav $^{5}$, Pashkevich Svetlana ${ }^{1}$, Sushko Timur ${ }^{1}$, Denisov Andrew ${ }^{1}$, Kletskov Alexey ${ }^{3}$, \\ Dosina Margarita ${ }^{1}$ and Pašukonienẻ Vita ${ }^{4}$ \\ ${ }^{1}$ Institute of Physiology, National Academy of Sciences, Belarus, Europe \\ ${ }^{2}$ Institute of Experimental Morphology, Pathology and Anthropology with Museum, Bulgarian Academy of Sciences, Sofia, Europe \\ ${ }^{3}$ Institute of Physical Organic Chemistry, National Academy of Sciences of Belarus, Minsk, Belarus, Europe \\ ${ }^{4}$ National Cancer Institute, Vilnius, Lithuania, Europe \\ ${ }^{5}$ Liege University, Liege, Belgium, Europe
}

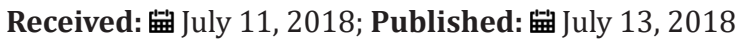

*Corresponding author: Kulchitsky Vladimir, Institute of Physiology, National Academy of Sciences, Belarus, Europe

Abbreviations: DNA: Deoxyribonucleic Acid; XV: XenogeneicVaccines; HC: Heterocyclic Compounds

\section{Introduction}

Despite the intensive efforts of researchers, the area of antitumor therapy still contains number of unsolved problems. Among the most general ones are: late diagnosis, poor efficiency of available therapies, multiple side effects [1-3]. In this article we briefly review some modern therapeutic methods used in oncology and describe recent attempts to neutralize the side effects of anticancer therapy.

\section{Classical Methods of Therapy for Patients with Oncological Diseases}

There are three general ways in tumor therapy: surgical intervention, radiotherapy and chemotherapy [4]. The combined application of these methods is often used. In addition, new specific treatments are being developed each year. Recently developed techniques allow selective detection and suppression of the tumor cells. The number of identified tumor cell markers grows in logarithmic progression. However, the percentage of successful outcomes for many types of malignant tumors is still far from ideal $[1,2]$.

Immunotherapy represents another approach to cancer treatment. It is based on the mobilization of the immune potential of the organism $[5,6]$. Vaccines activating immunocompetent cells are rather perspective as they improve the ability of these cells to identify and destroy tumor loci $[7,8]$. Family of cancer vaccines includes autologic and allogenic cell-based vaccines, Deoxyribonucleic acid (DNA) vaccines, vaccines based on dendritic cells and some others [8]. Utilization of cancer vaccines, however, meets some problems. Among them are variability of antigenic spectrum and expression level of the particular antigen; ability of tumor cells to escape from the immune response due to immunological editing; low immunogenicity level of tumor-associated antigens. Due to this specialist distinguish a particular subclass of cancer vaccines - xenogenic vaccines (XV) - as especially perspective. In contrast to the other cancer vaccines, $\mathrm{XV}$ ones contain antigens from nonhuman species. Structural difference from the human analogs makes them highly immunogenic and highly effective against some forms of malignant tumors [7-9]. Moreover, XV are able to stimulate antitumor reactions in the weakened organism with suppressed immune system. This is especially important for the cases of late diagnostic. We have to emphasize, however, that effectiveness of XV was demonstrated only in certain forms of cancer [7-9].

Some promising approaches in the diagnosis and treatment of tumors appeared due to the development of cell technologies. Some of the antigens expressed by the tumor cells at various stages of their life are associated with stem cell antigens [4,10]. A peculiar phenomenon of identical "fingerprints" was revealed in the study when spectra of rat 66 glioma cells and mesenchymal stem cells were compared using Raman spectroscopy [10]. The observed similarity might explain the difficulties faced by the immunocompetent cells when they need to discriminate among undifferentiated elements of tumor and non-tumor origin [10]. This might lead to the failures in the detection of tumor agents by the immune cells favoring further development of the pathological process.

\section{Nanotechnology in Modern Oncology}

Development of nanotechnology opened another innovative way in the diagnosis and treatment of cancer. Wide-known 
nanomaterials, such as nanoparticles (fullerenes, dendrimers) and heterocyclic compounds (HC), appear to have an antitumor effect. Nanoparticles were shown to act on different levels - from intracellular to systemic. For example, selective accumulation and clustering of gold nanoparticles froming plasmon nanopubes in tumor cell allows using short laser pulses to destroy the tumor nidus without significant damage to the surrounding healthy tissue [11]. Dendrimers maintaining the stability of medicinal substances and promoting their penetration into the cell represent another example of application of the nanoparticles in the clinical practice $[12,13]$. Due to their positive additive effect nanomaterials can be used in combination with antitumor drugs allowing to decrease the dose of the cytostatics known for their adverse side effects [12-14].

\section{Prospects for Improving the Efficiency of Therapy of Tumors Patients}

We would like to unfold the idea expressed in the last sentence of the previous section. Each pharmaceutical company seeks to develop medications with minimal side effects preserving their therapeutic efficacy. However, in spite of some selectivity of the action achieved in the modern chemotherapeutic agents, each chemotherapy course provokes a massive damage of healthy cells in the patient's organism. Such side effects of cytostatic significantly reduce the life expectancy of the patients. One of the strategies able to improve this situation is a combination of standard chemotherapy drugs with a kind of adjuvants $[14,15]$. These adjuvants might lack an antitumor effect by themselves. Instead, their main action would be catalyzation, or amplification of the cytostatics' action. The good candidates for this role are the above-mentioned nanoparticles and HC. In experimental conditions their combination with chemotherapeutic medications provided a cumulative effect increasing the antitumor action of the treatment. Introduction of such technology will allow reducing the effective dose of cytostatics, which in turn should decrease the adverse effects of the therapy $[14,15]$.

\section{Conclusion}

In conclusion, the two principal goals of any medical treatment are: increase of its effectiveness, and reduction of the costs. Combination of the chemotherapy with adjuvants (nanoparticles, HC) will allow reducing the doses of cytostatics while preserving or even improving the efficacy of treatment. This approach should also minimize the adverse effects of the chemotherapy and let on the cost savings [16-18].

\section{Acknowledgement}

This pooled analysis was funded by 000 "Synergy", and by grant IEMAM-BAS\&IP-NASB-BRFFI, and by grant NCI-L\&IP-NASB.

\section{References}

1. Torre LA, Bray F, Siegel RL, Ferlay J, Lortet Tieulent J, et al. (2015) Global cancer statistics, 2012. CA Cancer J Clin 65: 87-108.
2. Siegel RL, Miller KD, Jemal A (2018) Cancer statistics. CA Cancer J Clin 68(1): 7-30.

3. Shield KD, Parkin DM, Whiteman DC, Rehm J, Viallon V, et al. (2016) Population Attributable and Preventable Fractions: Cancer Risk Factor Surveillance, and Cancer Policy Projection. Curr Epidemiol Rep 3(3): 201-211.

4. Lee BS, Cho YW, Kim GC, Lee DH, Kim CJ, et al. (2014) Induced phenotype targeted therapy: Radiation-induced apoptosis-targeted chemotherapy. J Natl Cancer Inst 107(2): 403.

5. Keibel A, Singh V, Sharma MC (2009) Inflammation, microenvironment, and the immune system in cancer progression. Curr Pharm Des 15(17): 1949-1955.

6. Grivennikov SI, Greten FR, Karin M (2010) Immunity, inflammation, and cancer. Cell 140(6): 883-899.

7. Kraśko JA, Žilionytė K, Darinskas A, Dobrovolskienė N, Mlynska A, et al. (2018) Postoperative unadjuvanted therapeutic xenovaccination with chicken whole embryo vaccine suppresses distant micrometastases and prolongs survival in a murine Lewis lung carcinoma model. Oncol Lett 15(4): 5098-5104.

8. Itoh K, Yamada A, Mine T, Noguchi M (2009) Recent advances in cancer vaccines: An overview. Jpn J Clin Oncol 39(2): 73-80.

9. Potebnya GP, Symchych TV, Lisovenko GS (2010) Xenogenic cancer vaccines. Exp oncol 32(2): 61-65.

10. Kulchitsky VA, Arzumanyan GM, Dosina MO, Mamatkulov KZ, Suziedelis $\mathrm{K}$, et al. (2016) Raman spectroscopy: Comparing the "fingerprints" of c6 glioma and mesenchymal stem cells. JSCRT 1(1): 1-9.

11. Lukianova Hleb EY, Ren X, Constantinou PE, Danysh BP, Shenefelt DL, et al. (2012) Improved cellular specificity of plasmonic nanobubbles versus nanoparticles in heterogeneous cell systems. PLoS ONE 7: 1-10.

12. Shcharbin D, Shcharbina N, Pedziwiatr Werbicka E, Javier de la Mata, Gomez-Ramirez R, et al. (2018) Phosphorus Dendrimers as Vectors for Gene Therapy in Cancer pp. 227-244.

13. Shcharbin D, Dzmitruk V, Shakhbazau A, Goncharova N, Seviaryn I, et al. (2011) Fourth Generation Phosphorus-Containing Dendrimers: Prospective Drug and Gene Delivery Carrier. Pharmaceutics 3(3): 458473.

14. Kulchitsky VA, Alexandrova R, Suziedelis K, Paschkevich SG, Potkin VI (2014) Perspectives of Fullerenes, Dendrimers, and Heterocyclic Compounds application in Tumor Treatment. Recent Patents on Nanomedicine 4(2): 82-89.

15. Potkin VA, Kletskov AV, Petkevich SK, Pashkevich SG, Kazbanov VV, et al. (2015) Synthesis of water soluble isoxazol-3-yl(isothiazol-3-yl) carboxamides and ureas containing amino acid residues-potential anticancer agents. Heterocyclic Lett 1(1): 11-19.

16. Kulchitsky VA, Potkin VI, Zubenko YS, Chernov AN, Talabaev MV, et al. (2012) Cytotoxic Effects of Chemotherapeutic Drugs and Heterocyclic Compounds at Application on the Cells of Primary Culture of Neuroepithelium Tumors. Medicinal Chemistry 8(1): 22-32.

17. Moore DC, McVey GN (2018) Cost savings analysis and toxicity audit of a bevacizumab dose rounding policy at a community cancer center. J Oncol Pharm Pract 24(1): 42-46.

18. Sun D, Andayani TM, Altyar A, MacDonald K, Abraham I (2015) Potential cost savings from chemotherapy-induced febrile neutropenia with biosimilar filgrastim and expanded access to targeted antineoplastic treatment across the European Union G5 countries: A simulation study. Clin Ther 37(4): 842-857. 


\section{ISSN: 2574-1241}

DOI: $10.26717 / B J S T R .2018 .06 .001411$

Kulchitsky Vladimir. Biomed J Sci \& Tech Res

(i) This work is licensed under Creative Commons Attribution 4.0 License

Submission Link: https://biomedres.us/submit-manuscript.php

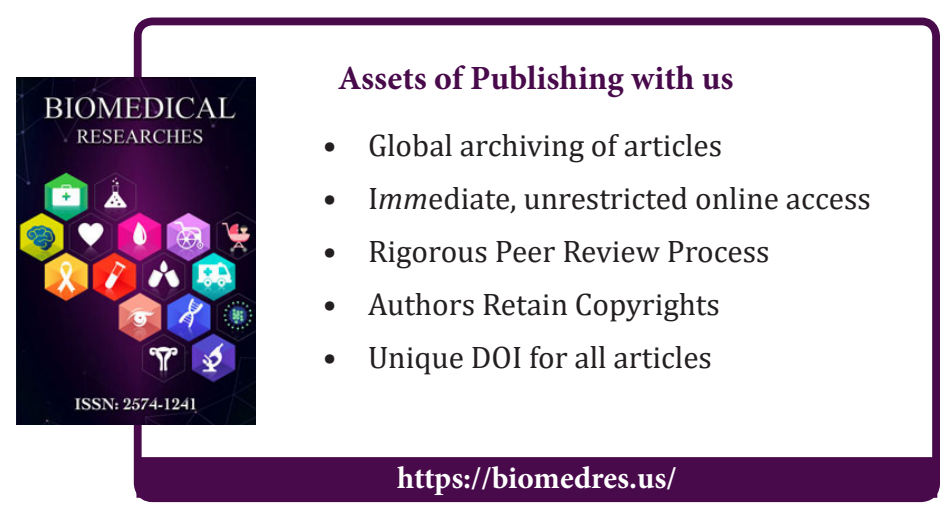

